\title{
Kistik Nefromalı Olguların Klinikopatolojik Özellikleri; Olgu Serisi
}

\author{
Berna AYTAÇ VURUŞKAN ${ }^{1}$, Sevda AKYOL ${ }^{1}$, Hakan VURUŞKAN ${ }^{2}$ \\ 1 Bursa Uludağ Üniversitesi Tıp Fakültesi, Tıbbi Patoloji Anabilim Dalı, Bursa. \\ 2 Bursa Uludağ Üniversitesi Tıp Fakültesi, Üroloji Anabilim Dalı, Bursa.
}

\section{ÖZET}

Kistik nefroma böbreğin nadir görülen multikistik benign tümörüdür. Hastanemizde 2005-2017 yılları arasinda 1625 hasta böbrekte kitle nedeniyle opere olmuştur. Bu hastaların \%1.2'si kistik nefroma tanısı almıştır.Çalışmamızda 2005- 2017 yılları arasında, kistik nefroma $\tan ı$ sı almış 20 olgu, retrospektif olarak incelenerek, klinik ve histopatolojik özellikleri ortaya konuldu. Hasta kayıtlarından elde edilen bilgiler, klinik hikâyeleri, klinik tanısı ve cerrahi materyalin histopatolojik özelliklerine göre not edildi. Olguların 15'i kadındı. Yaş aralığı 1 63 arasındaydı. 12 vakada lomber veya yan ağrısı şikayeti mevcuttu. 14 hastaya radikal, 6 hastaya parsiyel nefrektomi yapıldı. Olguların takiplerinde rekürrens görülmedi. Kistik nefromalar klinik ve radyolojik olarak diğer kistik renal tümörlerle karışabilir, ayırıcı tanıda histopatolojik inceleme gereklidir.

Anahtar Kelimeler: Kistik nefroma. Böbrek. Erişkin. Pediatrik.

Clinicopathologic Features Of Cystic Nephroma; Series of Cases

\section{ABSTRACT}

Cystic nephroma is a rare multicystic benign tumor of kidney. In our hospital, 1625 patients were operated because of a kidney mass between 2005 and 2017. 1.2\% of these patients were diagnosed as cystic nephroma. In our study we evaluated retrospectively the clinical and histopathologic features of 20 patients with cystic nephroma that were diagnosed between 2005-2017. Demographics of patients, clinical history, clinical diagnosis and pathologic characteristics of the specimen were assessed. 15 patients were female. Ages ranged from 1 to 63 years. 12 patients had lomber or flank pain. 14 patients underwent radical and 6 patients underwent partial nephrectomy. There was no recurrence during follow-up. Cystic nephromas mimic other cystic renal neoplasms clinically and radiologically, necessitating histopathological examination for definitive diagnosis.

Key Words: Cystic nephroma. Kidney. Adult. Pediatric.

Kistik nefromalar (KN) böbreğin nadir görülen multikistik benign tümörleridir ${ }^{1}$. Tüm renal tümörlerin yaklaşık \% 1-2'sini oluşturur². Etiyolojisi belirsizdir ve histogenezi tartışmalıdır ${ }^{3}$. Bimodal dağılım gösterirler, pediatrik ve erişkin yaş grubunda histogenetikmorfolojik olarak farklı hastalıklar olarak tanımlanmışlardır. Pediatrik yaş grubunda 3 ay - 2 yaş arasında ve erkeklerde sık görülürken, erişkin yaş grubunda 30 yaşından daha büyük ve kadın cinsiyette baskın olarak görülmektedir ${ }^{4}$. Pediatrik KN, metanefrik dokudan kaynaklanan benign karakterde tümörler iken erişkin

Geliş Tarihi: 25 Ekim 2018

Kabul Tarihi: 16 Temmuz 2019

Dr. Sevda AKYOL

Bursa Uludağ Üniversitesi Tıp Fakültesi,

Tıbbi Patoloji Anabilim Dalı,

Bursa

Tel.: 02242953680

E-posta: sevdaakyol1@gmail.com
KN daha çok mikst epitelyal stromal tümörün (MEST) kistik lezyonu olarak değerlendirilmektedir ${ }^{5,6}$. Kistik nefromalar belirleyici preoperatif tanı özellikleri bulunmadığ için günümüzde cerrahi tedavi edilmesi gereken lezyonlar olarak yerini korumaktadır ${ }^{7}$. Bu çalışmada tanı almış $20 \mathrm{KN}$ olgusu geriye dönük olarak incelenerek ayırt ettirici klinik ve patolojik özellikleri analiz edilmiştir.

\section{Gereç ve Yöntem}

Çalışmamıza Ocak 2005 ve Mayıs 2017 tarihleri arasında, tanı almış $20 \mathrm{KN}$ olgusu dahil edildi. Hastalara ait klinik bilgiler dosyalarından, ameliyat materyallerine ait patoloji raporları ile örnekleri Patoloji bölümünden sağlandı. Preparatlar tekrar değerlendirmek için çıkarıldı. Hastalara preoperatif olarak uygulanan radyolojik görüntüleme yöntemleri ve raporları gözden geçirilerek not edildi. 


\section{Bulgular}

Olguların klinik bilgileri Tablo-I'de verilmiştir. Hastaların çoğu yan ağrısı şikayeti ile başvurmuştur $(12 / 20, \% 60)$. Klinik öyküler incelendiğinde 8 hastada eşlik eden çeşitli kronik hastalıklar mevcut iken 1 hastada diğer böbrekte renal hücreli karsinoma tespit edilmiştir. Ultrasonografide kistler genellikle hiperekoik septalar ile çevrelenmiş hipoekoik lezyonlar şeklinde raporlanmıştır. Bilgisayarlı tomografi görüntüleme yönteminde, böbrek içerisinde iyi sınırlı septasyonlar içeren multikistik yapılanmalar şeklinde tanımlanmıştır. Hastaların hiç birinde kalsifikasyon veya perinefrik değişiklik görülmemiştir. Pediatrik 1 hastada ve tümör boyutu küçük saptanan 5 hastada parsiyel nefrektomi uygulanırken, 14 hasta tümör boyutu ve tümörlerin geniş damar yapılarına yakınlığı nedeniyle radikal nefrektomi operasyonu uygulanmıştır. Operasyon sonrası gönderilen materyallerin makroskobik incelemelerinde tümöral lezyonlar tamamen kistik, multiloküle özellikte olup kistlerin iç yüzeyi düzgün görünümde izlenmiştir (Şekil 1). Mikroskobik incelemede kistlerin küboidal veya hobnail tarzı epitel ile döşeli olduğu, kistler arasındaki stromanın ise değişen derecede hiyalinize iğsi hücrelerden, fibroblastlardan oluştuğu ve yer yer over stromasını andıran bir görünüme sahip olduğu dikkati çekmiştir (Şekil 2). Her iki komponentte de sitoloijk atipi görülmemiştir. İmmünohistokimyasal olarak, stromal komponentte CD10, düz kas aktini, östrojen reseptör (ER), progesteron reseptör(PR) ile pozitiflik saptanmıştır (Şekil $3,4)$. Hastalarda postoperatif herhangi bir komplikasyon gelişmemiştir. Olguların takip aralığı 1-96 ay olup hastalarda rekürrens veya metastaz görülmemiştir.

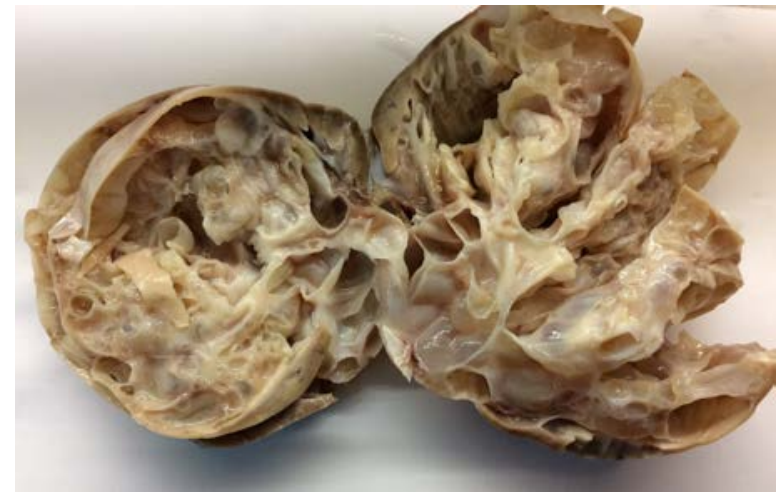

Şekil 1:

Makroskopik olarak tümörler kistik ve multiloküle olup, kistlerin iç yüzeyi düzgün görünümdedir.

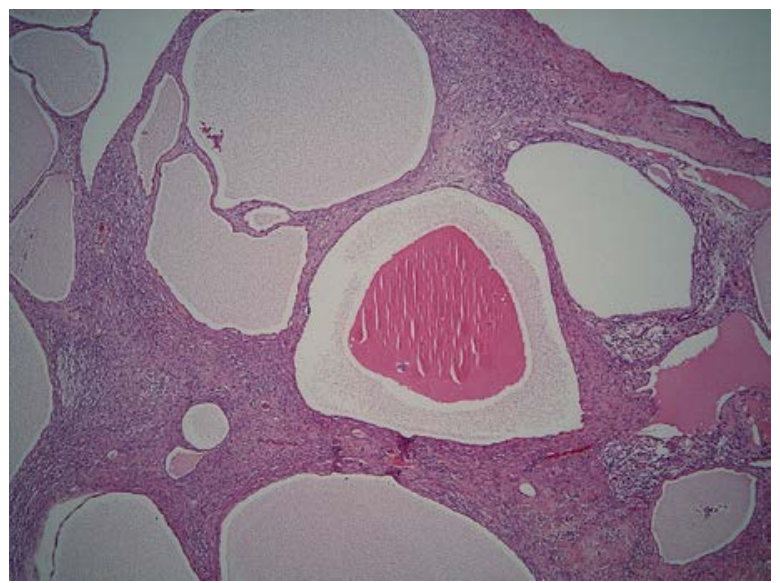

Şekil 2:

Basıklaşmış epitelle döşeli farklı çaplardaki kistler ve bu kistler arasında yerleşmiş iğsi hücrelerden oluşan stroma ( HE x 100)

Tablo I. Kistik nefroma tanısı almış olguların klinik özellikleri.

\begin{tabular}{|c|c|c|c|c|c|c|c|c|}
\hline Olgular & Yaş & Cinsiyet & Semptom & Lateralite & $\begin{array}{l}\text { Tümör boyutu } \\
\text { (cm) }\end{array}$ & $\begin{array}{c}\text { Tedavi } \\
\text { (Nefrektomi) }\end{array}$ & $\begin{array}{l}\text { Takip süresi } \\
\text { (ay) }\end{array}$ & Prognoz \\
\hline 1 & 45 & K & Ağrı & Sol & 7 & Total & 76 & Sağ \\
\hline 2 & 59 & $E$ & İnsidental & Sağ & 1,2 & Parsiyel & 1 & Sağ \\
\hline 3 & 1 & E & Şişlik & Sağ & 4 & Total & 96 & Sağ \\
\hline 4 & 2 & K & Şişlik & Sağ & 15 & Total & 35 & Sağ \\
\hline 5 & 63 & K & Ağrı & Sağ & 13 & Total & 60 & Sağ \\
\hline 6 & 33 & K & İnsidental & Sağ & 1,1 & Parsiyel & 56 & Sağ \\
\hline 7 & 42 & E & Ağrı & Sol & 10 & Total & 55 & Sağ \\
\hline 8 & 24 & K & Ağrı & Sol & 9 & Total & 36 & Sağ \\
\hline 9 & 59 & $\mathrm{~K}$ & Ağrı & Sağ & 3 & Total & 1 & Sağ \\
\hline 10 & 30 & K & İnsidental & Sağ & 3,2 & Total & 1 & Sağ \\
\hline 11 & 8 & $E$ & Ağrı & Sağ & 3 & Parsiyel & 24 & Sağ \\
\hline 12 & 59 & K & Ağrı & Sol & 6 & Total & 27 & Sağ \\
\hline 13 & 38 & $E$ & Ağrı & Sol & 4 & Total & 12 & Sağ \\
\hline 14 & 14 & K & Ağrı & Sol & 6 & Parsiyel & 15 & Sağ \\
\hline 15 & 50 & K & Ağrı & Sol & 20 & Total & 4 & Sağ \\
\hline 16 & 46 & K & Ağrı & Sol & 15 & Total & 12 & Sağ \\
\hline 17 & 63 & K & İnsidental & Sağ & 3,7 & Parsiyel & 12 & Sağ \\
\hline 18 & 2 & K & Şişlik & Sağ & 12 & Total & 5 & Sağ \\
\hline 19 & 54 & K & Ağrı & Sağ & 9 & Total & 1 & Sağ \\
\hline 20 & 44 & K & İnsidental & Sol & 5 & Parsiyel & 1 & Sağ \\
\hline
\end{tabular}

K:Kadın, E: Erkek 


\section{Kistik Nefroma}

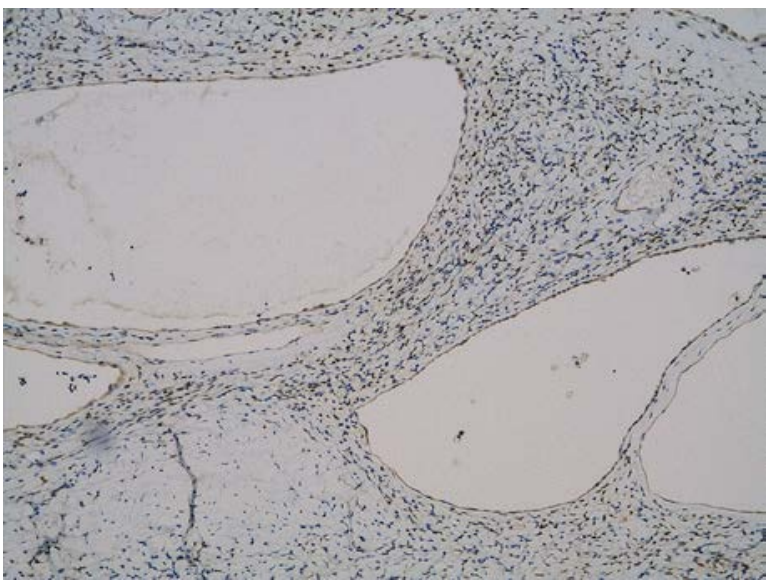

Şekil 3:

Stromal hücrelerde ER pozitifliği ( H.E $\times 100$ )



SSekil 4:

Stromal hücrelerde SMA pozitifliği ( H.E x 100)

\section{Tartışma}

KN, önceleri literatürde multiloküler kistik tümör, renal multiloküler kist, multipl loküler kistik nefroma, renal kistadenoma ve parsiyel polikistik böbrek adları ile tanımlanmış olup malign potansiyelli gelișimsel lezyonlar olarak düşünülmüşstür ${ }^{8,9} .2004$ Dünya Sağlık Örgütü renal tümörler sinıflamasında, pediatrik kistik nefromalar ayrı bir antite olarak yer almayı kistik parsiyel diferansiye nefroblastoma ve kistik nefroblastoma'nın bir bölümü olarak değerlendirilmiştir ${ }^{10}$. Erişkin tip KN ise böbreğin yumuşak doku tümörleri sınıflaması içerisinde ayrı bir başlık olarak yer almıştır $^{11}$. Ancak 2016 yilında yayınlanan yeni Dünya Sağlık Örgütü renal tümörler sınıflamasında erişkin tip $\mathrm{KN}$, benzer yaş ve cinsiyet dağılımı, morfolojik görünümü ve immünohistokimyasal profili temel alınarak MEST ailesinin bir bölümü olarak değerlendirilmiştir $^{12}$. Pediatrik KN ise DICER1 gen mutasyonu gösterdiği için kistik parsiyel diferansiye nefroblastoma ve kistik nefroblastomadan farklı ayrı bir antite olarak ele alınmıştır ${ }^{13}$. Literatür bilgilerinde pediatrik ve erişkin tip KN'lerin birbirleri ile benzerlikleri bilin- mektedir ancak farklarını karşılaştıran çok az sayıda yayın bulunmaktadır. Li ve ark. göre, DICER-1 gen mutasyonu pediatrik hastalarda belirgin yüksektir. Aynı zamanda stromal değişiklikler daha çok erişkin tip KN/MEST ailesinde görülmektedir ${ }^{14}$. Yazarlara göre, over stroması benzeri stroma, dağılmış görünümde kollajen ve inhibin immünreaktivitesi erişkin tip KN/MEST'de saptanırken, pediatrik KN'de bu tarzda morfolojik ve immünohistokimyasal belirteç gösterilememiştir ${ }^{14}$. Bizim olgularımızdan pediatrik tip kistik nefroma tanısı almış hastalara DICER-1 gen mutasyon analizi yapılmamış olup histopatolojik değerlendirme sonucunda tanıya ulaşılmıştır.

Klinik olarak, sıklıkla fizik muayene sirasında saptanan asemptomatik abdominal şişlik ile ortaya çıkar ${ }^{3}$. Bunun yanında ağrı, hematüri veya üriner sistem enfeksiyonu gibi nonspesifik semptomlar da gösterebi$\operatorname{lir}^{15}$. Hematüri her yaş grubunda görülebilir ve tümörün renal pelvise doğru uzanımı ile ilişkilendirilebiliir ${ }^{15}$. Pediatrik yaş grubu daha çok ağrısız abdominal kitle ile bulgu verir ${ }^{16}$. Olgu serimizde boyutu küçük saptanan tümörler başka nedenlerle yapılan görüntüleme yöntemleri sırasında insidental saptanırken, $4 \mathrm{~cm}$ üstünde büyük boyutlu tümörlere sahip 2 hastada şişlik, 8 hastada yan ağrısı saptanmıştır. Hematüri şikayeti tanımlayan hasta tespit edilmemiştir.

Literatürde görüntüleme yöntemleri ile ilgili ayırt edici özellikler tanımlanmıştır ancak bunlar tüm hasta tiplerini kapsayacak özellikte değildir. Ultrasonografi ve Bilgisayarlı Tomografi (BT) görüntüleme yöntemleri multiloküler karakterde neoplazileri gösterebilir ancak Bosniak sınıflamasındaki tip II veya III ayır1mını yapması çok güçtür ${ }^{17}$. Bu lezyonlar BT'de iyi sinırlı multiseptasyonlu kistik lezyonlardır ve septasyonları fark edilebilir derecede artmıștır. Cok nadir olarak artmış septasyonların bir araya gelmesi solid kitle lezyonunu ile karışabiliri ${ }^{18}$. Manyetik rezonans (MR) görüntüleme yöntemi nadir olarak kullanılır. Ancak T1 ağırlıklı kesitlerde hipointens ve T2 ağırlıklı kesitlerde hiperintens sinyal gösterir. Septalar tüm kesitlerde fibröz içerik nedeniyle genellikle hipointenstir ${ }^{19}$. Ancak hiçbir yöntem çocuklarda kistik nefroma ile diğer çocukluk çağ kistik böbrek tümörlerini, erişkinlerde ise renal hücreli karsinoma ile ayırımını güvenilir şekilde yapamaz ${ }^{20,21}$. Bu nedenle kesin tanı cerrahi materyalin patolojik incelemesi sonrası konulmaktadır.

Patolojik incelemede ise $\mathrm{KN}$ tanısinda Powell ve ark. tarafindan oluşturulan ve en son Joshi, Beckwith tarafindan geliştirilen kriterler mevcuttur. Bu kriterlere göre lezyon; net bir şekilde normal böbrek parankiminden ayrılmalı, septalarla ayrılmış değişik boyutlarda kistlerden oluşmalı, kistler basıklaşmış kuboidal veya hobnail hücrelerinden oluşan epitelle döşeli olmalı, septalar fibröz dokudan oluşmalı ve iyi diferansiye renal tübülleri içerirken tamamıyla gelişmiş nefron bulundurmamalıdır ${ }^{22}$. Patolojik incelemede pediat- 
rik hastalarda ayırıcı tanıya kistik parsiyel diferansiye nefroblastoma (KPDN) ve kistik nefroblastoma alınmalıdır. KN'da dahil olmak üzere tüm bu tümörler makroskopik olarak genelde unifokaldir ancak nadiren multifokal veya bilateral olabilir. Lezyon boyutları 5 $10 \mathrm{~cm}$ arasında değişmektedir ve kalın fibröz kapsüle sahiptir. Kistin lokülleri birkaç milimetre ile $4 \mathrm{~cm}$ arasında değişmektedir, miksoid veya berrak sıvı içerir. Kistler arasında ince fibröz septa mevcuttur. Ancak mikroskobik incelemede KN'de kistler arası septalar matür tübülleri içerirken KPDN'de blastemal hücreler ve/veya embriyonel elemanlar saptanır. Benzer şekilde blastemal hücre kümelerinin varlığı kistik nefroblastoma tanısını koydurur ${ }^{23}$. Erişkin hastalarda ise ayırıcı tanıda en önemli yeri, radyolojik veya klinik olarak ayırımın çok zor olabileceği renal hücreli karsinoma almaktadir ${ }^{7}$. KN'de kistler kuboidal veya hobnail tarzı epitel ile döşelidir ${ }^{24}$. Stroma değişik derecelerde hiyalinize iğsi hücreler, fibroblastlar ve az sayıda matür renal tübül yapıları içerir. Renal hücreli karsinomda görülmesi beklenen, kistleri döşeyen, berrak sitoplazmalı atipik hücreler veya septalarda berrak sitoplazmalı atipik hücre grupları bulunmaz.

Böbreğin diğer malign kistik tümörlerini dışlamak açısından cerrahi yaklaşım önerilen tedavi yöntemidir. Nefron koruyucu cerrahiler lezyonun bulunduğu yer ve boyutuna bağlı olarak uygulanabiliir ${ }^{25}$. KN erişkinlerde benign tümörler olarak değerlendirilir ancak parsiyel nefrektomili olgularda tümör rekürrensi de bildirilmiştir ${ }^{26}$. Literatürde Castillo ve ark. sundukları 24 olguluk parsiye nefrektomi olgu serisinde 39 aylık takip sonrasında rekürrens görülmemiştir ${ }^{27}$. Olgular1mızın 14'ünde tümör boyutunun büyüklüğü ve görüntüleme yöntemleri ile renal hücreli karsinoma ayırımının net olarak yapılamaması nedeniyle nefrektomi uygulanmıştır. Pediatrik olgularımızda ise daha çok nefroblastamöz tümör grubu düşünülerek total cerrahi yapılmıştır. Çalışmamızda hastaların hiçbirinde rekürrens tespit edilmemiştir.

\section{Sonuç}

İlerleyen tanısal görüntüleme yöntemleri bu tip renal tümörlerin farkındalığını arttırmakla beraber, nonspesifik klinik bulguları ve görüntüleme yöntemlerinde benzer bulguların görülmesi nedeniyle kistik renal tümörlerde nefrektomi en iyi tedavi seçeneği gibi görülmektedir. Lezyonun boyutuna ve yerine bağl1 olmak koşuluyla, kapsüllü lezyonlarda ve kistin benign olduğundan şüphenilmiyorsa nefron koruyucu cerrahi tedavi seçeneği olabilir. Ancak kesin tanı tamamıyla çıkarılmış tümörün histopatolojik değerlendirilmesi ile konulabilir.

\section{Kaynaklar}

1. Bonsib SM. Cystic nephroma. Mixed epithelial and stromal tumor. In: Eble JN, Sauter G, Epstein JL, Sesterhenn IA(eds).Pathology and genetics of tumors of the urinary system and male genital organs; WHO classification of tumours. Lyon: IARCPress; 2004. p. 76.

2. Han KR, Janzen NK, McWhorter VC, et al.Cystic renal cell carcinoma: biology and clinical behaviour. Urol Oncol 2004;22:410-4.

3. Dell'Atti L. An Unusual Presentation of Cystic Nephroma in an Adult Man. Rare Tumors. 2015;18: 5860

4. Mohanty D, Jain BK, Agrawal V, Gupta A. Cystic nephroma:Adiagnostic dilemma. Saudi J Kidney Dis Transpl 2010;21:518-20.

5. Van Den Hoek J, De Krijger R, Van De Ven K, LequinM,Van Den Heuvel-Eibrink MM. Cystic nephroma, cystic partially differentiated nephroblastoma and cystic Wilms' tumor in children:A spectrum with therapeutic dilemmas. Urol Int 2009;82:65-70.

6. Zhou M, Kort E, Hoekstra P, et al. Adult cystic nephroma and mixed epithelial and stromal tumor of the kidney are the same disease entity: Molecular and histologic evidence. Am J Surg Pathol 2009;33:72-80.

7. Wilkinson C, Palit V, Bardapure M, et al. Adult multilocular cystic nephroma: Report of six cases with clinical, radiopathologic correlation and review of literature. Urol Ann 2013;5:13-7.

8. Kuzgunbay B, Turunc T, Bolat F, KilincF.Adult cystic nephroma: a case report and a review of the literature. UrolOncol2009;27:407-9.

9. Falidas E, Ntasi A, Mathioulakis S, et al.Multicystic nephroma in an elderly man.Case report. G Chir 2011;32:483-6.

10. Eble J. Cystic partially differentiated nephroblastoma. In: EbleJN,Sauter G, Epstein JI, Sesterhenn IA (eds). World Health Organization Classification of Tumours Pathology and Genetics of Tumours of the Urinary System and Male Genital Organs. Lyon: IARC Press; 2004:55.

11. Bonsib SM. Cystic nephroma. In: Eble JN, Sauter G, EpsteinJI,Sesterhenn IA (eds). World Health Organization Classification of Tumours Pathology and Genetics of Tumours of the Urinary System and Male Genital Organs. Lyon: IARC Press; 2004:76.

12. Michal M, Amin MB, Delahunt B, et al. Mixed epithelial stromal tumor family. In: Moch H, Humphrey PA, Ulbright TM, ReuterVE (eds). World Health Organization Classification of Tumors:Pathology and Genetics of Tumors of the Urinary System and Male Genital Organs, 4th ed. Lyon: IARC Press; 2016:70-71.

13. Argani P, Bruder E, Dehner L, et al. Paediatric cystic nephroma. In:Moch H, Humphrey PA, Ulbright TM, ReuterVE (eds). World Health Organization Classification of Tumors: Pathology and Genetics of Tumors of the Urinary System and Male Genital Organs,4th ed. Lyon: IARC Press; 2016:53.

14. Li Y, Pawel BR, Hill DA, Epstein JI, Argani P. Pediatric Cystic Nephroma Is Morphologically, Immunohistochemically, and Genetically Distinct From Adult Cystic Nephroma.Am J SurgPathol 2017;41:472-81.

15. Bouhafs A, Cherradi N, Lamaalmi N, Beklachem R, Barahioui M. An unusual case of multicystic Nephroma with prominent renal pelvis involvement. IntJ Urol 2006;13:436-8.

16. Zdrojowy R, Sawicz-Birkowska K, Apoznański W, et al. Adult Wilms tumour.Int Urol Nephrol 2011;43:691-6.

17. Bisceglia M, Galliani CA, Senger C, et al.Renal cystic diseases: a review. Adv Anatom Pathol 2006;13:26-56. 


\section{Kistik Nefroma}

18. Chu LC, Hruban RH, Horton KM, Fishman EK. Mixed epithelial and stromal tumor of The kidney: radiologic-pathologic correlation.Radiographics 2010;30:1541-51.

19. Silver IM, Boag AH, Soboleski DA. Best cases from the AFIP: Multilocular cystic renal tumor: cystic nephroma. Radiographics 2008;28: 1221-5.

20. Grosse C, Sonnberger U, Grosse A, Breinl E, HerganK. Multilocular cystic nephroma: Atypical sonographic and computed tomographic findings. EurJ RadiolExtra 2006; 58:13-16.

21. 21.Boybeyi O, Karnak I, Orhan D et al. Cystic nephroma and localized renal cystic disease in children: diagnostic clues and management. J Pediatr Surg 2008;43:1985-89

22. 22.Joshi VV, Beckwith JB. Multilocular cyst of the kidney (cystic nephroma) and cystic, partially differentiated nephroblastoma. Terminology and criteria for diagnosis. Cancer. 1989;64:466-79.
23. Agrons GA, Wagner BJ, Davidson AJ, Suarez ES. Multilocular cystic renal tumor in children: Radiologic-pathologic correlation. Radio Graphics1995;15:653-69.

24. 24.Mukhopadhyay S, Valente AL, de la Roza G. Cystic Nephroma: A histologic and immunohistochemical study of 10 cases. ArchPathLabMed2004;128:1404-11.

25. Dong B, Wang Y, Zhang J, et al. Multilocular cystic nephroma treated with laparoscopic nephron-sparing surgery: a case report. Can UrolAssoc J 2014;8:e545- 7.

26. Bastian PJ, Kulhmann R, Vogel J, Bastian HP. Local recurrence of an unilateral cystic nephroma. Int J Urol 2004;11:329-31.

27. Castillo OA, Boyle ET Jr, Kramer SA. Multilocular cysts of kidney. A study of 29 patients and review of literature. Urology 1991;37:156-62. 
